\title{
REVISÁO INTEGRATIVA: LETRAMENTOS DO IDOSO E OS CÍRCULOS DE CULTURA FREIREANOS
}

\section{INTEGRATIVE REVIEW: ELDERLY'S LITERACY AND FREIRE'S CIRCLES OF CULTURE}

\author{
Daniel Aguiar Pereira \\ Doutorando em Gerontologia na Universidade Estadual de Campinas. \\ Docente na Universidade Nove de Julho. São Paulo - SP - Brasil \\ danielpaguiar@uni9.pro.br
}

Eliane Feitoza Oliveira Doutora em Linguística Aplicada pelo Instituto de Estudos da Linguagem da Universidade Estadual de Campinas. Docente do curso de Pedagogia da Faculdade Polis das Artes. Embú das Artes - SP - Brasil eli_feitoza@yahoo.com.br

Meire Cachioni

Doutora em Gerontologia pela Universidade Estadual de Campinas. Professora da Faculdade de Ciências Médicas da Universidade Estadual de Campinas e Coordenadora da Graduação em Gerontologia da Escola Artes e Humanidades/USP. Campinas - SP - Brasil

meirec@usp.br

\begin{abstract}
Resumo: No contexto brasileiro, de modo geral, desde o início da década de 1980, as pesquisas sobre leitura e escrita têm se concentrado em situaçóes de ensino e aprendizagem relacionadas a crianças e jovens em fase de escolarização. Apenas nos últimos anos, alguns pesquisadores brasileiros têm contemplado, por diferentes prismas teórico-metodológicos, questóes de leitura e escrita relacionadas às práticas de letramento de idosos. Tendo em vista esse cenário, este artigo, de base bibliográfica, constitui-se a partir de uma revisão integrativa em bases de dados científicas. A busca se deu com os seguintes descritores e suas combinaçôes na língua portuguesa e inglesa - "letramento + idoso" e "literacy + older people", transitando entre os campos da Educação, da Linguística Aplicada e da Saúde. Objetiva traçar um panorama de como o letramento do idoso tem sido tratado em alguns artigos acadêmico-científicos, a fim de entendermos as diferentes correntes teórico-metodológicas que embasam estudos que tematizam as práticas escriturais da população idosa e como essas práticas impactam a vida deles. Nessa perspectiva apresentada, o letramento do idoso pode também ser compreendido e analisado a partir do escopo teórico-metodológico dos Novos Estudos do Letramento e a partir do que entendemos como um exemplar do modelo epistemológico de letramento: o Círculo de Cultura Freiriano. Dos dados levantados corrobora-se a necessidade de ampliar a compreensão sobre práticas de leitura e de escrita no contexto da Gerontologia, da Educaçâo e da Linguística Aplicada, a fim de promover atividades que possibilitem ao idoso efetivar seus direitos básicos de cidadão.
\end{abstract}

PalaVras-chaves: Educação. Idoso. Letramentos. 
Abstract: In the Brazilian context, in general, since the beginning of the 1980s, research on reading and writing has focused on teaching and learning situations related to children and youngsters in schooling. Only in the last years, some Brazilian researchers have considered, through different theoretical and methodological prisms, questions of reading and writing related to the literacy practices of the elderly. In view of this scenario, this article, based on a bibliographical basis, is based on an integrative review of scientific databases. The search was carried out with the following descriptors and their combinations in the Portuguese and English language - "letramento + idoso" e "literacy + older people", passing between the fields of Education, Applied Linguistics and Health. the literacy of the elderly has been dealt with in some academic-scientific articles in order to understand the different theoreticalmethodological currents that support studies that focus on the scriptural practices of the elderly population and how these practices impact on their lives. In this perspective, the literacy of the elderly can also be understood and analyzed from the theoreticalmethodological scope of the New Studies of Literature and from what we understand as an exemplar of the epistemological model of literacy: the Círculo de Cultura Freiriano. The data gathered confirm the need to broaden the understanding of reading and writing practices in the context of Gerontology, Education and Applied Linguistics, in order to promote activities that enable the elderly to realize their basic rights as citizens.

KEYwORDs: Education. Elderly. Literacy.

\section{Introduçáo}

Em âmbito mundial, os estudos de letramento desenvolvidos a partir da década de 1980 buscaram investigar a relação entre leitura e escrita e seus usos sociais. Essas pesquisas procuraram evidenciar, entre outros aspectos, que: (a) o ensino e a aprendizagem da leitura e da escrita náo se esgotam na apreensão de um processo de codificação e decodificação; (b) as práticas de leitura e escrita não nasciam das e tão pouco estariam restritas às práticas escolarizadas. Desse modo, esses pesquisadores (SCRIBNER; COLE, 1981; HEATH, 1982; STREET, 1984, entre outros) trouxeram à tona o fato de que as práticas sociais de leitura e escrita implicam situaçôes concretas vividas pelos sujeitos na vida cotidiana e em diferentes contextos, de modo que o letramento, além de ser entendido como uma prática social, pode ser entendido também como a relação de uso que as pessoas estabelecem com a leitura e a escrita nesses variados contextos. (TERZI, 2005; 2006)

Assim, a partir da primeira década do século XXI, alguns estudiosos (STREET, 2003; LANKSHEAR; KNOBEL, 2007) têm procurado 
demonstrar que não passamos por um único processo de letramento, mas por processos de letramentos e, por isso, o mais adequado é usarmos o termo no plural. Ou seja, passamos, ao longo da vida, por processos de aprendizagem e uso da leitura e da escrita, inseridos em contexto social, cultural, político e econômico específicos. Isso nos leva a crer que a aprendizagem da leitura e da escrita é um processo contínuo e não se restringe à fase inicial de escolarização, pois, conforme vamos, ao longo da vida, nos inserindo em contextos sociais, enfrentamos o desafio de lidar com novas práticas de letramento, e esse processo não é diferente para o idoso, principalmente, para os que vivem em uma sociedade grafocêntrica.

Essa perspectiva social e histórica sobre os estudos do letramento influenciou tanto a produção acadêmica brasileira sobre leitura e escrita quanto à produçáo sobre práticas pedagógicas de ensino e aprendizagem de crianças, jovens, adultos, universitários e, mais recentemente, de idosos. Em virtude do nosso interesse voltar-se para a população idosa, faz-se neste artigo um levantamento sobre o tema 'Letramento e Idoso', com o objetivo de compreender como está circulando no Brasil o conceito de letramento voltado para as práticas escriturais dessa populaçáo ou como práticas de letramento impactam em suas vidas, quando inseridos em contexto de escolarização.

\section{Metodologia}

Para chegar a essa compreensão, apresentamos, em um primeiro momento, os principais pressupostos dos Novos Estudos do Letramento visto defendermos que esse escopo teórico é produtivo para compreender as práticas escriturais ou práticas de ensino e aprendizagem voltadas às pessoas idosas, justamente por adotar uma perspectiva social, histórica e cultural do letramento.

Apresentamos, na próxima seção, uma revisão integrativa sobre artigos encontrados que tratam do tema 'letramento do idoso'. A revisão integrativa trata-se de uma metodologia que segundo Souza; Silva; e Carvalho (2010) ajusta dados da literatura teórica e empírica, além de incorporar um vasto leque de propósitos: definição de conceitos, revisão de teorias e evidências, e análise de problemas metodológicos de um tópico particular. 
Dessa forma, pode-se reconhecer espaços de conhecimento, identificar o conhecimento já produzido e indicar diretrizes para futuros estudos.

Para esta revisão foi realizada uma busca com os descritores e suas combinaçôes na língua portuguesa ("letramento + idoso") e inglesa ("literacy + older people") nas seguintes bases de dados: AgeLine, Web of Science LILACS, PubMed, CINAHL, Scopus e Cochrane, objetivando encontrar artigos publicados com essa temática e cujos resumos pudessem apontar um panorama do tratamento acadêmico dado ao letramento do idoso no contexto de pesquisa brasileiro, bem como quais são as tendências teórico-metodológicas que embasam esses estudos, com referência ao período de 2009 a 2017.

Nessa busca foram encontrados doze artigos, publicados entre os anos de 2009 a 2017. Os critérios de inclusão definidos para a seleção dos artigos foram: i) artigos publicados em português, inglês e espanhol; ii) artigos na íntegra que retratassem a temática referente ao Letramento do idoso e iii) artigos publicados e indexados nos referidos bancos de dados nos últimos dez anos.

A análise dos estudos selecionados, em relação ao delineamento de pesquisa, pautou-se em Whittemore e Knaf (2005), Stetler et. al. (1998), Ganong (1987), Lüdke e André (2012), Street e Lefstein (2007), Terzi (2006); Lea e Street (1998); Gee (2001) e Barton (1994), sendo que tanto a análise quanto a síntese dos dados extraídos dos artigos foram realizadas de forma descritiva, possibilitando observar, contar, descrever e classificar os dados, com o intuito de reunir o conhecimento produzido sobre o tema explorado na revisão.

A amostra final desta revisão foi constituída de sete artigos científicos, selecionados pelos critérios de inclusão previamente estabelecidos. Desse conjunto, foram selecionados os trabalhos de Amodeo, Maria Netto e Fonseca (2010); Souza Filho (2011); Souza Filho e Massi (2014); Souza Filho, Massi e Ribas (2014); Gamburgo, 2009; Massi et al. (2010; 2015); Torquato, Massi e Santana (2011), por julgarmos, pela leitura dos trabalhos, que, de fato, tratam da associação entre letramento e idoso, com foco em uma concepção autônoma de letramento ou calcada em uma educação bancária. (STREET, 1984; FREIRE, 1981)

Posteriormente, discutimos os motivos pelos quais entendemos o Círculo de Cultura Freiriano como um exemplar do modelo epistemo- 
lógico de letramento, a fim de também defendermos que esse modelo de letramento pode ser eficaz para o desenvolvimento do letramento do idoso em contexto de escolarização. Vale salientar, que nessa seção, tentamos promover um adensamento entre os estudos de Freire e os estudos oriundos da corrente teórica dos Novos Estudos do Letramento. Por fim, tecemos as consideraçóes finais.

\section{O escopo teórico dos Novos Estudos do Letramento e o Modelo Epistemológico de Letramento}

As décadas de 1960 e de 1970, no que diz respeito aos estudos relacionados à escrita, foram marcadas por investigaçóes científicas que se propuseram a observar quais eram as características da língua oral e da língua escrita, a partir de uma visão dicotômica, a fim de investigar os impactos causados pela introdução da escrita em sociedades de tradição oral e comprovar o argumento de que uma cultura é intelectualmente superior à outra por ter adquirido a tecnologia da escrita. (STREET, 1984)

Em outras palavras, as teorias que surgiram dessas investigaçóes científicas, realizadas nas áreas da psicologia e as quais pertencem ao conjunto de trabalhos que, segundo Street (1984), convencionou-se chamar de a Grande Divisa entre oralidade e escrita, procuraram postular que havia diferenças cognitivas entre as pessoas e as sociedades que utilizavam a escrita como principal meio de comunicação e àquelas cujas comunicaçóes se restringiam à linguagem oral.

Dentre as investigações que seguiam essa vertente epistemológica, Street (1984) destacam-se os trabalhos de Havelock (1963), Goody (1968), Greenfield (1972) e Hyldyard e Olson (1978). Esses teóricos, que pertencem à corrente epistemológica da Grande Divisa, entendem que a aquisição da escrita resulta em consequências do uso da linguagem escrita, no sentido de permitir um nível maior de abstração em oposição à linguagem oral, dependente do contexto social; resulta também no desenvolvimento de processos de raciocínio mais complexos, traçando uma oposição entre pensamento lógico/científico e pré-lógico, bem como entre história e mito. Além disso, esses estudiosos acreditavam que o letramento levava ao de- 
senvolvimento econômico e ascensão social das sociedades e dos indivíduos que o adquirisse. (OLIVEIRA, 2011; 2015)

Street (1984), ao proceder sua crítica aos trabalhos desenvolvidos pelos teóricos da Grande Divisa, ressalta que, neles, a escrita é tida como neutra, pois independe dos processos social-histórico-culturais que condicionam os usos que os indivíduos fazem dela em contextos sociais variados. Sendo assim, Street rejeita as ideias que postulam um grande fosso entre oralidade e escrita, por entender que essas duas modalidades da língua, apesar de ocorrerem em contextos específicos e servirem também para fins específicos de comunicação, interpenetram-se em outros contextos sociais.

Além disso, o autor enquadra essas pesquisas naquilo que chama de Modelo Autônomo de Letramento, justamente por ver o letramento como habilidade meramente técnica, e propóe o Modelo Epistemológico de Letramento, que leva em consideração os aspectos sociais, históricos que influenciam o uso da escrita, de modo que os significados que a escrita tem para determinado grupo social são dependentes dos contextos e instituições em que essa modalidade da língua foi adquirida. (KLEIMAN, 1995)

No que diz respeito ao modelo, ele pressupóe que a escrita, de forma autônoma e independente dos fatores sociais que condicionam seu uso, terá efeitos sobre outras práticas sociais e operaçóes de ordem cognitiva, tais como o desenvolvimento cognitivo - no qual as capacidades de ler e escrever estão situadas em cada pessoa - a ascensão social e o desenvolvimento econômico (TERZI, 2006; STREET, 2003 citados por Oliveira, 2017). Segundo Oliveira (2017), na sala de aula, define-se esse modelo como a capacidade de ler e escrever, em que ler significa ser capaz de decodificar as palavras e escrever ser capaz de codificar a língua dentro de uma forma visual, o texto. Entendemos, bem como Rojo (ROJO, 2004, p. 03), que essas capacidades abrem as portas para o mundo da leitura e da escrita, "[...] mas que absolutamente náo esgotam as capacidades envolvidas no ato de ler" e de escrever.

Já o modelo epistemológico, segundo Street (1984; 1995; 2003), concebe o letramento como uma prática social, e não como uma habilidade técnica ou neutra. Assim, o letramento não se desvincula do contexto cultural e social no qual é construído, bem como do significado atribuído à escrita pelas pessoas e das relaçóes de poder que regem os seus usos, de modo que a junção desses fatores resulta em letramentos múltiplos, 
que variam de comunidade para comunidade, por conta das condiçóes socioeconômicas, culturais e políticas que as influenciam. (TERZI, 2006; STREET, 2003)

Para se contrapor aos estudos desenvolvidos pelos teóricos da Grande Divisa - que, segundo Street (1984), além de evidenciarem as consequências cognitivas do letramento, dentro de uma visão dicotômica, consideram a escrita como independente dos processos sócio históricos que condicionam as relaçôes que construímos com os outros por meio da escrita - surge o que o autor e Gee (1996) denominam de Novos Estudos do Letramento. Essa área inaugurou uma nova maneira de compreender o letramento: variável dependente dos contextos sociais nos quais a língua escrita se inscreve, ou seja, essa área entende o letramento como prática social.

No que diz respeito aos interesses de pesquisa, a área dos NLS concentrou-se, inicialmente, em investigaçóes dos usos culturais que comunidades, sociedades e grupos sociais faziam da escrita, a partir da observação do cotidiano dos indivíduos e das relaçôes que estabeleciam com a escrita. As três pesquisas que, na voz de Oliveira $(2011 ; 2015)$ colaboraram, inicialmente, para o desenvolvimento da área, a partir da visão sociocultural da escrita, foram a de Scribner e Cole (1981), Heath (1983), Street (1984), seguidas das pesquisas de Barton (1994), Gee (1996), Barton e Hamilton (2000).

Esses teóricos definiram os principais pressupostos teóricos que balizam a área dos NLS. Dentre eles, o conceito de práticas e eventos de letramento. Heath (1983), por exemplo, definiu o termo eventos de letramento como qualquer situação na qual o texto escrito é parte constitutiva da natureza das interaçóes dos participantes e de seus processos interpretativos.

O conceito de eventos de letramento presente no estudo de Heath serviu de base para Street (1995) elaborar a noção de práticas de letramento e estabelecer as devidas relaçôes entre os dois conceitos. Essa noção, tida pelo autor como modos culturais de utilizar a escrita, possui um caráter abstrato, uma vez que as práticas de letramento não podem ser totalmente observadas em atividades nas quais o texto escrito é parte constitutiva das interaçóes entre os sujeitos, pois envolvem todo o significado que é atribuído pelos participantes e pela instituição à atividade ou à tarefa de leitura e escrita em contexto interacional específico. 
Em virtude de os eventos de letramento surgirem das práticas sociais de leitura e escrita e serem moldados por elas, Barton e Hamilton (2000) destacam que muitos eventos apresentam aspectos regulares, ao passo que outros são condicionados pelos procedimentos e expectativas das agências de letramento, como o local de trabalho, a igreja, a escola, a universidade, etc. Nas vozes de Street e Lefstein (2007), a repetição dos eventos, ao longo do tempo, se transforma em uma prática, de modo que para essa transiçáo ser observada faz-se necessário que os eventos sejam descritos sistematicamente através de seus componentes imediatos, a saber: contexto da interação, participantes, textos e recursos materiais utilizados, ações dos participantes durante o evento, sequências, etc. Street, com a publicação do livro Literacy in Theory and Practice, em 1984, explicita a ideia do letramento a partir de seu caráter social e cultural. Nesse trabalho, o autor não só expóe as características do modelo autônomo de letramento, mas também concebe o modelo epistemológico de letramento - conforme descritos acima - tomando, como unidade de análise, as práticas de letramento influenciadas pelos modos socioculturais com as quais os indivíduos, comunidades, sociedades interagem e fazem uso da escrita.

Ao expor o caráter social do letramento, Street (1984; 1995; 2003) chama a atenção para a existência de múltiplos letramentos, não só por conta das diferentes práticas sociais que utilizam a escrita, mas em virtude dos avanços tecnológicos e das mudanças nos arranjos sociais, que exigem dos indivíduos, além das competências oral e escrita, habilidades para lidar com outros modos de representação que coadunam as linguagens verbal, visual, gestual, entre outras.

Com base no exposto, é possível dizer que os trabalhos desenvolvidos no âmbito da área NLS estabeleceram os pressupostos teóricos que servem ao propósito de analisar, de uma perspectiva social e cultural: os modos como as pessoas lidam com as demandas de escrita em diferentes contextos, quais os significados que o letramento têm para as elas, as relaçóes de poder que estấo no bojo dos usos que fazem da escrita, os modelos de letramento prevalentes em determinados contextos sociais, bem como os letramentos que estão em concorrência nesses contextos, entre outros aspectos (OLIVEIRA, 2015). Por ter essas características, acreditase, neste artigo, que os pressupostos teóricos dos NLS podem auxiliar na compreensão da relação que a população idosa estabelece com atividades 
orais e escritas, uma vez que dada a inatividade socialmente convencionada à velhice, práticas sociais de leitura e escrita caem em desuso, o que implicaria no declínio de funçôes cognitivas básicas, a exemplo, da memória e da linguagem.

Ainda é válido dizer que os teóricos dos NLS, principalmente Barton (1994), destacam o trabalho de Paulo Freire, no que concerne a alfabetização de jovens e adultos, como ancorado a uma perspectiva sociocultural de letramento. Sendo assim, defende-se neste trabalho que o Círculo de Cultura se aproxima do modelo epistemológico de letramento, o que será discutido posteriormente, na terceira seção deste artigo.

\section{Pesquisas sobre o Letramento do Idoso}

Segundo pesquisa de Projeção da população do Brasil por sexo e idade/2000-2060 (IBGE, 2013), o significativo crescimento da longevidade humana e, por conseguinte, do número de idosos no mundo, faz necessário considerar as discussóes que cercam a ideia de autonomia e qualidade de vida destes sujeitos. Nesse sentido, para a almejada qualidade de vida no processo de envelhecimento é imprescindível que sejam disponibilizadas propostas capazes de suportar as questóes individuais e sociais destas pessoas, em processo de envelhecimento e de pessoas idosas.

Uma destas propostas de suporte ao idoso, que oportunizam o acesso de compreensão dessas questôes próprias ao seu universo, são atividades que encontram subsídio no trabalho com a linguagem, pois é por meio dela que estabelecemos a relaçáo do eu no mundo e do eu com o mundo. Assim o uso da linguagem está em conscientizar-se, ler-se, escrever-se, existenciar-se e historicizar-se. (TODARO; PEREIRA, 2015)

Desse modo, dá-se ênfase ao papel que a linguagem escrita adquire no processo de envelhecimento por motivos basilares, a saber: (a) o crescente número de idosos com diferentes graus de letramento que o Brasil apresenta; (b) a sociedade atual está imersa na linguagem oral, escrita e multimodal.

No cenário acadêmico, escassos são os trabalhos científicos que foram desenvolvidos na tentativa de melhor compreender a relação da população idosa com atividades discursivas orais e escritas, ou seja, com 
práticas de letramentos. Dessa forma, pode-se perceber a incipiência de artigos científicos publicados sobre Letramentos do Idoso, uma vez que se trata de uma área pouco explorada no campo da Saúde, da Educação e da Linguística Aplicada. Nesse contexto, apresenta-se, de forma sucinta, o que vem sendo discutido pela comunidade acadêmica sobre a temática: letramentos do idoso.

Souza Filho (2011), Souza Filho, Massi e Ribas (2014) e Gamburgo et.al. $(2007 ; 2009)$ analisaram as condições de letramento de pessoas com idade mínima de 65 anos, comparando tais condições entre idosos que têm grau de instrução compatível com nível superior completo e aqueles que não têm, ou ainda sujeitos alfabetizados em relação a não alfabetizados. Já as pesquisas de Massi (2010; 2015) e Torquatto, Massi e Santana (2011) analisaram as condiçóes de letramento de sujeitos com idade superior a 60 anos, revelando que, de forma geral, pessoas idosas apresentam também uma relaçáo restrita com a escrita.

Os pesquisadores apontam para a necessidade de ampliar a compreensão sobre práticas de leitura e de escrita no contexto da gerontologia, de forma a beneficiar nossa sociedade a médio e longo prazo de forma expressiva, com a promoção de atividades, que possibilitem ao idoso efetivar seus direitos básicos de cidadáo. Sugere uma atenção especial, por parte da sociedade civil organizada, bem como da comunidade científica, para ampliação da compreensão sobre práticas de leitura e de escrita no contexto do envelhecimento.

Nestes trabalhos (MASSI, 2015; SOUZA FILHO, 2011; TORQUATTO, MASSI e SANTANA 2011; AMODEO, 2010; GAMBURGO, 2009) é possível observar que os sujeitos idosos investigados tinham acesso fácil a diversos materiais de leitura, mas o vínculo com esses materiais ainda era deficitário. Independentemente do nível de escolaridade, verificou-se a utilização restrita de práticas relacionadas com a linguagem escrita, visto que tanto os idosos que possuíam formação superior quanto àqueles que não a tinham apresentaram dificuldades significativas para extrair informaçóes de textos simples.

Esse tipo de estudo que compara capacidades de leitura e escrita e adotam a perspectiva do déficit, ou seja, apontando o que os participantes da pesquisa não fazem ou têm dificuldades para fazer, ao invés de problematizar também o que fazem e o porquê fazem, são criticadas pelos autores 
que integram a corrente teórica dos Novos Estudos do Letramento, pois não analisam as práticas escriturais dos sujeitos tendo como pano de fundo suas histórias pregressas de letramento, que podem estar calcadas em uma perspectiva autônoma de letramento (STREET, 1984) ou no que Freire (1981) chamou de educação bancária - dado que justificaria o fato de não localizarem informaçôes simples em textos de curta ou média extensão.

Talvez esses sujeitos apresentem dificuldades significativas com a leitura e a localização de informaçóes,capacidade básica de leitura, por virem de uma história de letramento que priorizou, no processo de escolarização, atividades de leitura e produção de textos escritos descontextualizadas, sem conexão com os contextos reais de produção da linguagem, orientadas para aquisição da norma padrão da língua, sem considerar os usos que já faziam, a fim de que competências individuais cognitivas fossem desenvolvidas, sem considerar os processos interativos que envolvem e ocorrem via uso da linguagem, pois

o modelo de letramento adotado para escolarização dos indivíduos, caracterizado por Street (1984) como autônomo, enfatiza sobremaneira o texto escrito, considerando-o como uma forma autônoma. Nessa perspectiva, a escrita é entendida como produto completo em si mesmo, cujos significados independem de fatores contextuais de produção. Sendo assim, o funcionamento lógico da escrita e os modos como as palavras se articulam em frases, períodos e parágrafos são vistos como aspectos suficientes para que os sujeitos participantes desse processo interpretem o texto escrito. Em outras palavras, o modelo autônomo parte do pressuposto de que "o letramento ocorre por meio da linguagem fora de contexto, do discurso autônomo e do pensamento analítico. (STREET, 1995, p. 154 apud OLIVEIRA, 2011, p.65).

Desse modo, para entender o porquê das dificuldades dos estudantes e problematizá-las, bem como o bom desempenho deles, a que se considerar outras variáveis, que náo só a falta de competência para ler e escrever, medidas, muitas vezes, a partir de testes que visam comparar competências e habilidades de "letrados" versus "iletrados", conforme faziam os teóricos 
da Grande Divisa. Vale salientar que esse tipo de teste ou pesquisa comparativa pré-estabelecem um pressuposto no mínimo preconceituoso - as pessoas ditas letradas são cognitivamente mais desenvolvidas em relação às "iletradas" - desconsiderando a prerrogativa de que um sujeito, principalmente inserido em uma sociedade grafocêntrica, tem algum nível de letramento, faz uso, mesmo que restrito, da leitura e da escrita para interagir.

Assim, grande parte das pesquisas investigadas (MASSI, 2015; SOUZA FILHO, 2011; TORQUATTO, MASSI, SANTANA, 2011; AMODEO, 2010; GAMBURGO, 2009) indicam que, embora os sujeitos estudados tenham amplo acesso a materiais escritos, não conseguem extrair informaçóes explicitamente apresentadas em textos simples, que circulam em nosso cotidiano.

Souza Filho (2011), Souza Filho e Massi (2014), Gamburgo et al. (2007; 2009), Massi (2010; 2015) e Torquatto, Massi e Santana (2011) concluem, em suas pesquisas, que é necessário desenvolver atividades de intervenção que possam trabalhar com a linguagem escrita e oral, para que sujeitos em processo de envelhecimento possam efetivamente inserir-se na sociedade grafocêntrica atual e terem qualidade de vida na velhice. Porém, para que os idosos possam efetivamente acessar os contextos sociais a que pretendem como cidadáos de fato e de direito, acredita-se que essas atividades de intervenção precisam estar calcadas no modelo epistemológico de letramento, pois esse modelo preconiza que as práticas de letramento se dão na e dependem da estrutura social, bem como são atravessadas pela ideologia.

Em outras palavras, a importância do modelo epistemológico de letramento para a emancipação dos sujeitos está na compreensão de que a aparente neutralidade das práticas de letramento - principalmente as escolarizadas - precisa ser substituída pela compreensão de que a participação consciente em práticas escriturais situadas pode promover a distribuição de poder na sociedade. Nesse sentido, uma abordagem crítica de letramento exige a elaboração de políticas de alfabetização criativas, emancipatórias, transformadoras, que contemplem a população idosa, refutando a ideia de que a alfabetização por si só funciona como um projeto civilizatório salvacionista de povos marginalizados, como os idosos, sendo a escola a única agência capaz de executar a alfabetização. 
Assim, é válido ressaltar que, em uma sociedade letrada, nem sempre aprender a ler e a escrever, ou seja, ser alfabetizado resultará na mobilidade social imediata e será trampolim para acesso a status social e bem materiais, bem como promoverá inserção em práticas privilegiadas socialmente, conforme assevera Street (2003). Para que os sujeitos se insiram nos contextos pretendidos, faz-se necessário que usem a escrita socialmente, pois tanto Freire (1981) quanto Street (1984) entendem que o acesso à cultura escrita, via processos de leitura, não pode ocorrer dissociado das condiçôes sociais, culturais, políticas, históricas dos sujeitos, ou seja, da realidade concreta dos envolvidos.

\section{O Círculo de Cultura de Paulo Freire e o Modelo Epistemológico de Letramento}

Nessa seção, não é nossa intenção promover uma discussão sistemática das obras de Paulo Freire, bem como dos conceitos desenvolvidos por ele (consciência, opressor, oprimido, alfabetização, etc.). Procuramos entender como o círculo de cultura figura como um exemplar do modelo epistemológico de letramento e, por isso, pode servir como modelo para a promoção do letramento do idoso.

No Brasil, em meados do século XX, os movimentos populares, alimentados pelos ideários Freireano de educação, estavam com a atenção voltada para a educaçáo de adultos. Paulo Freire e um grupo de educadores comprometidos com educação popular e mudança social sistematizaram uma concepção de educação, com vistas a dar outra intencionalidade a esta prática. (GADOTTI, 2005)

Fundamentando-se em uma concepção dialógica de educação, Paulo Freire sugeria "a investigação dos temas geradores como fonte de prática educativa” (SOUZA, 2011, p. 24), a fim de resgatar saberes populares à sala de aula, para a promoção de uma educaçáo voltada não apenas à decodificação de letras e números, mas que gere consciência, libertação e emancipação, o que também está previsto na concepção epistemológica de letramento. Por esse prisma, formulou uma concepçáo de alfabetizaçáo e letramento que a tem como o próprio ato de conhecimento, como compreensão do homem e do homem no mundo. (FREIRE, 1987) 
Para o autor, o ato de ler não deve ser entendido como mera decodificação, pois ler implica entender também o contexto que cria e sustenta os significados da leitura do mundo. James Paul Gee (1996), um dos pesquisadores que integram a área dos Novos Estudos do Letramento, também considera a leitura como um processo que deve emergir da cultura e assevera que as crianças que são submetidas ao processo de leitura para compreender o mundo, na perspectiva cultural, podem ter mais êxito na escola, diferentemente daquelas que são submetidas ao ensino da leitura restrito ao contexto escolar, dentro de uma perspectiva meramente instrucional ou domesticadora.

Nesse sentido, é válido dizer que Freire sempre procurou dissecar os efeitos dos letramentos vernaculares dos dominantes (BARTON, 1994) na formação da pessoa humana e com essa compreensão dar sentido ao ato de educar, de modo que é possível dizer que o autor foi um dos pioneiros em discutir as práticas de letramento, só não cunhou o termo, como fizeram os autores dos Novos Estudos do Letramento.

Assim, fica evidente que os estudos de Freire subsidiaram os estudos do letramento internacionalmente. Em virtude disso, entende-se que as elaboraçôes teóricas em torno do termo letramento são releituras que muitos autores estrangeiros fizeram de Paulo Freire, de modo que é possível dizer que "uma alfabetização meramente de domínio do código, a fim de instrumentalizar os indivíduos para absorver mecanismos de inserção no mercado de trabalho, ou seja, preparação para a manutenção da superação de classes (FREIRE, 1987, p.45) é o que Street (1984) chamou de modelo autônomo de letramento.

Já o modelo epistemológico de letramento pode ser associado à concepção dialógica de educação discutida por Paulo Freire, na qual "existe uma preocupação com o desenvolvimento da consciência política, mediante trabalho coletivo e a valorização da prática social dos sujeitos do processo educativo" (SOUZA, 2011, p. 116), ou seja, preocupação esta que também pode ser vista nos trabalhos de estudiosos que integram a corrente teórica dos Novos Estudos do Letramento, principalmente de Barton (1994) e Street (1984), que entendem os pressupostos teóricos de Freire como calcados em uma perspectiva social, cultural, política e econômica de letramento. 
Portanto, o letramento torna-se o ato educativo em si, o que gera continuidade nos estudos e emancipaçáo humana - uma consciência de mundo e de vida. Uma abordagem que se caracteriza pela busca da interação entre homem e mundo, sendo o sujeito protagonista, elaborador e criador de seus conhecimentos (GADOTTI, 2005). Logo, o homem é pensado a partir dos pressupostos de sua cultura, de sua vida em sociedade. É compreendido como o sujeito que se constrói e se repensa no e para o processo de vida de ensino e aprendizagem. (SOUZA, 2011)

Assim, esse processo é desenvolvido com vistas à superação da relação tradicional de educação, a relação entre opressores e oprimidos, pois não há verticalidade na relação, embora o professor se reconheça mediador do processo de aquisição de conhecimento (FREIRE, 1996). Desse modo, a abordagem metodológica ao educar deveria estar ancorada no diálogo e na problematização dos conteúdos escolares e sua relação com o mundo que os cerca, sendo este processo repensado e reconstruído junto ao sujeito que produz conhecimento. (FREIRE, 1987)

Paulo Freire, falecido em 1997, deixou-nos seu legado a partir de relevantes contribuições sobre a concepção dialógica de educação, sobretudo nas obras: Educação como Prática de Liberdade, 1967, e Pedagogia do Oprimido, 1970, de modo que essas obras foram basilares para os autores que integram a corrente teórica dos Novos Estudos do Letramento.

Embora Freire não tenha cunhado o termo, é possível dizer que o Círculo de Cultura foi pensado a partir de uma concepção epistemológica de letramento, pois o círculo oferece uma visão com maior sensibilidade cultural das práticas de letramento locais, reconhecendo que o letramento é uma prática de cunho social, e não uma habilidade técnica e neutra, que aparece sempre envolto em princípios epistemológicos socialmente construídos, conforme aponta Street (2003), ou em volto em práticas de letramento dominantes.

Quanto ao Sistema Freire de Alfabetização, a obra de Carlos Rodrigues Brandão intitulada O que é método Paulo Freire, aponta-nos diretrizes para a ação, sugerindo algumas etapas para o trabalho. Na referida obra, o autor descreve as etapas do processo de alfabetização e letramento segundo Paulo Freire, Brandão sistematiza e descreve de forma metodológica os caminhos a serem percorridos pelos sujeitos em processo de aquisição e desenvolvimento da linguagem. 
Segundo Brandáo (1987), o círculo está em toda a etapa do processo de letramento apregoado por Paulo Freire, "estão todos à volta de uma equipe de trabalho que náo tem um professor ou um alfabetizador, mas um animador de debates que, como um companheiro alfabetizado, participa de uma atividade comum em que todos ensinam e aprendem." (BRANDÃO, 1987, p. 43)

Embora as primeiras experiências de uma educação dialógica tenham ocorrido em meados dos anos de 1960, esta discussão é extremamente contemporânea, como nos aponta Brandáo (1987), pois as discussões sobre a concepção dialógica, ou o método Paulo Freire, estão vigentes em muitas localidades do Brasil e do mundo. A atualidade do pensamento de Paulo Freire vem sendo atestada pela multiplicidade de experiências que se desenvolvem tomando o seu pensamento como referência, em diferentes áreas do conhecimento, ao redor do mundo (GADOTTI, 2005). A exemplo disso, há uma quantidade de universidades distribuídas pelo país que mantêm projetos de extensão nessa modalidade de educação e produzem cadernos para o letramento (SOUZA, 2011, p. 134-5). Assim, trabalhar com uma racionalidade dialógica ou emancipatória significa

trabalhar com a racionalidade emancipatória significa estabelecer uma relação dialética entre o currículo e o contexto histórico, social, político e cultural como um todo. Construir/reformular/reorientar o currículo nessa perspectiva requer, antes de tudo, uma nova compreensão que explicite uma dimensão frequentemente oculta da questáo curricular que diz respeito à ideologia. Conceber o currículo sob a ótica da racionalidade emancipatória implica compreendê-lo como um processo dependente da participação dos sujeitos envolvidos na ação educativa. (SAUL; SILVA, 2009, p. 225)

As práticas de letramentos para idosos podem e devem ser pensadas a partir de uma concepçáo dialógica de educação e pautadas pelo modelo epistemológico de letramento, de modo que, neste caso, sugere-se pesar esta prática fundamentando a ação no método de Paulo Freire. Pensar estratégias pedagógicas que visam não só desenvolver as habilidades da linguagem (leitura e escrita), mas também desenvolver um processo de au- 
tocrítica de cada indivíduo, sempre com a preocupação de contextualizar os conteúdos culturais de acordo com a realidade dessa população, ou seja, uma educação que procure desenvolver a tomada de consciência e a atitude crítica mesmo na velhice. Segundo Paulo Freire, os círculos ao serem realizados permitem maior apropriação do sujeito em trânsito de cultura.

Dessa forma, perceber que a utilização da concepção dialógica de educação, manifesta pelo Círculo de cultura Freireano, aplicado a idosos, implicaria um repensar a autonomia deste sujeito, de modo a alterar a percepção de si no mundo e para o mundo. Além disso, acredita-se que esta prática voltada à construção de uma nova concepção acerca do conhecimento apresenta-se como preditor de qualidade de vida na velhice e para o processo de envelhecimento. Se queremos promover na velhice a mudança dos paradigmas - particular/individual e o genérico/social, oferecendo aos futuros educadores da velhice e do envelhecimento uma transformação da vida do sujeito idoso, para a tomada de consciência, libertaçáo, emancipação e autonomia -, faz-se necessário balizar os projetos de intervenção em um modelo epistemológico de letramento, o qual é contemplado no Círculo de Cultura, conforme procuramos defender neste artigo.

\section{Consideraçóes finais}

A utilização da concepção dialógica de educação, manifesta pelo Círculo de Cultura Freireano aplicado a idosos, compreendido dentro do modelo epistemológico de letramento, implicaria um repensar a autonomia deste sujeito na velhice, de modo a alterar a percepçáo de si no mundo e para o mundo (TODARO; PEREIRA, 2015). Ao se reconhecer o letramento do idoso como prática social, que contribui para o desenvolvimento das habilidades da linguagem (leitura e escrita) e do pensar autocrítico dessa populaçáo, promove-se uma tomada de consciência e a emancipaçáo deste sujeito para uma velhice autônoma e participativa no corpo social.

Sob esta ótica, corrobora-se com os dados levantados (MASSI, 2015; SOUZA FILHO, 2011; TORQUATTO, MASSI E SANTANA 2011; AMODEO, 2010; GAMBURGO, 2009) ao discutir-se o letramento do idoso como prática social, ao sugerir que este sujeito não tenha sido ensinado na escola a conhecer e praticar os diferentes modelos le- 
trados. Assim, inserir esta população idosa no trânsito da cultura leitora e escritora pode oportunizar mudanças neuropsicológicas significativas impactando em melhores condiçóes de autonomia, qualidade de vida e inserção em práticas sociais letradas. Dessa forma, defender que o idoso imerso nestas práticas de letramento, neste caso a proposta do Círculo de Cultura Freireano, pode oferecer ao idoso o desenvolvimento e manutenção das funções cognitivas, conativa e executivas superiores, a exemplo da memória e da linguagem, a fim de que tenha uma vida mais saudável e participativa.

\section{Referências}

AMODEO, M. T.; MARIA NETTO, T.; FONSECA, R. P. Desenvolvimento de programas de estimulação cognitiva para adultos idosos: modalidades da Literatura e da Neuropsicologia. Letras de Hoje, Porto Alegre, v. 45, n. 3, p. 54-64, jul./set. 2010.

BARTON, D. Literacy: an introduction to the ecology of written language. London: Blackwell, 1994.

BARTON, D.; HAMILTON, M. Literacy Practices. In: BARTON, D; HAMILTON, M.; IVANIC, R. (Org.). Situated literacies: reading and writing in context. New York: Routledge, p. 7- 15, 2000.

BRANDÃO, Carlos Rodrigues. O que é método Paulo Freire. 13. ed. São Paulo: Brasiliense, 1987.

SOUZA FILHO, P. P. S. Condiçōes de letramento no processo de envelhecimento: uma análise junto a idosos com mais de 65 anos [tese]. Curitiba: Universidade Tuiuti do Paraná, 2011.

SOUZA FILHO, P. P. S; MASSI, G. A. A.; RIBAS, A. Escolarização e seus efeitos no letramento de idosos acima de 65 anos. Rev. Bras. Geriatr. Gerontol., Rio de Janeiro, 2014; 17(3):589-600.

SOUZA FILHO, P. P.S; MASSI, G. A. A. Letramento de idosos brasileiros acima de 65 anos. Revista: Distúrb Comun, São Paulo, 26(2): 267-276, junho, 2014.

FREIRE, P. Pedagogia do oprimido. 17.ed. Rio de Janeiro: Paz e Terra, 1987. - Pedagogia da Autonomia: saberes necessários à prática educativa. São Paulo: Paz e Terra, 1996. . Educação e Mudança. Rio de Janeiro: Paz e Terra, 1981. 
GADOTTI, M. Educação de jovens e adultos: correntes e tendências. In: GADOTTI, M.; ROMÃO, J. E. (Org.). Educação de jovens e adultos: teoria prática e proposta. 7.ed. Sáo Paulo: Cortez, 2005.

GAMBURGO, L.J.L. \& MONTEIRO, M.I.B. Envelhecimento e linguagem: algumas reflexóes sobre aspectos cognitivos na velhice. Rev Kairós 2007.

Singularidades do envelhecimento: reflexóes com base em conversas com idosos institucionalizados. Interface Comum Saúde Educ, vol.13, n.28, pp.31-41, 2009.

GEE, J. P. Social linguistics and literacies: ideology in Discourses. 2nd ed. London/ Philadelphia: The Farmer Press, 1996.

. Reading as situated language: a sociocognitive perspective. In: Journal of Adolescent \& Adult Literacy. Newark, v. 8, n. 44, p. 714-725, 2001.

GOODY, J. (ed) Literacy in Traditional Societies. Cambridge University Press, 1968.

GREENFIELD, P. Oral or written language: the consequences for cognitive development in Africa, u.s. and England in language and speech, n. 15, 1972.

INSTITUTO BRASILEIRO DE GEOGRAFIA E ESTATÍSTICA (IBGE). Projeção da População do Brasil por Sexo e Idade para o Periodo 2000-2060. 2013. Disponível em: https://ww2.ibge.gov.br/home/estatistica/populacao/projecao_da_populacao/2013/ default.shtm. Acessado em: 17 jul. 2018.

HAVELOCK, E. Preface to Plato. Cambridge: Havard University Press, 1963.

HEATH, S. B. What no bedtime story means: narrative skills at home and school. In: Language in society, v. 1, n. 2, p. 46-79, 1982.

Ways with words. Cambridge: Cambridge University Press, 1983.

HILDYARD, A. OLSON, D. Literacy and the specialization of language. Manuscrito não publicado. Ontario Institute of Studies in Education, 1978.

KLEIMAN, A. (org.) Os significados do letramento: uma perspectiva sobre a pratica social da escrita. Campinas: SP: Mercado de Letras, 1995.

LANKSHEAR, C.; KNOBEL, M. Sampling the 'new' in new literacies studies. In Lankshear, C.; Knobel, M. A new literacies sampler. New York, Peter Lang, 2007. Disponível em: http://everydayliteracies.net/files/NewLiteraciesSampler_2007.pdf, Acesso: 18 jul. 2018.

LEA, M.R.; STREET, $B$. Student Writing in higher education: an academic literacies approach. Studies in Higher Education, London, v. 23, n. 2, p. 157-16, June, 1998.

LUDKE, M; ANDRÉ, M. Pesquisa em Educação: abordagens qualitativas.

(Reimpressão). São Paulo: EPU, 2012.

MASSI, G. J. et al. Linguagem e envelhecimento: práticas de escrita autobiográfica junto a idosos. CEFAC, ; 17(6), 2065-2071, nov./dez. 2015. 
MASSI, G. et al. Práticas de letramento no processo de envelhecimento. Rev. Bras. Geriatr. Gerontol., Rio de Janeiro, 2010; 13(1):59-71

OLIVEIRA, E. F. Letramento Acadêmico: concepçóes divergentes sobre o gênero resenha crítica. Dissertação (Mestrado em Linguística Aplicada) - Universidade Estadual de Campinas, SP, 2011.

OLIVEIRA, E.F. Letramentos acadêmicos : o gerenciamento de vozes em resenhas e artigos científicos produzidos por alunos universitários. Tese (Doutorado em Linguística Aplicada) - Universidade Estadual de Campinas, SP, 2015.

OLIVEIRA, E.F. A vertente teórica dos letramentos acadêmicos no âmbito dos Novos Estudos do Letramento. Revista Educação e Linguagens, Campo Mourão, v. 6, n. 11, jul./dez. 2017.

OLIVEIRA, M. Jovens e adultos como sujeitos de conhecimento e aprendizagem. XXII Reuniáo Anual da ANPEd; Caxambu, 1999.

SAUL, A. M.; SILVA, A. F. G. O legado de Paulo Freire para as políticas de currículo e para a formaçáo de educadores no Brasil. Revista Brasileira de Estudos Pedagógicos, Brasília, v. 90, n.224, p. 223-244, jan./abr., 2009.

SCRIBNER, S.; COLE, M. The psychology of literacy. Cambridge: Harvard University, 1981.

SOUZA, Maria Antônia de. Educação de jovens e adultos. 2. ed. Curitiba: Ibpex, 2011.

SOUZA, Marcela Tavares de; SILVA, Michelly Dias da; CARVALHO, Rachel de. Revisão integrativa: o que é e como fazer. Einstein (São Paulo), São Paulo , v. 8, n. 1, p. 102-106, Mar. 2010.

STETLER C.B. et al. Utilization-focused integrative reviews in a nursing service. Appl Nurs Res. 1998;11(4):195-206.

STREET, B. V. Literacy in theory and practice. London: Cambridge University Press, 1984. (org.) Cross-Cultural Approaches to Literacy. Cambridge: Cambridge University Press, 1993.

. Literacy in theory and practice. London: Cambridge University Press, 1984.

. Social literacies: critical approaches to literacy development, ethnography, and education. London: Longman, 1995.

Abordagens alternativas ao letramento e desenvolvimento. Paper entregue após a Teleconferência UNESCO Brasil sobre letramento e diversidade, 2003.

; LEFSTEIN, A. Literacy: an advanced resource book. London/New York: Routledge, 2007.

TERZI, S.B. Mudancas na concepcao de escrita de jovens e adultos em processo de letramento. Revista Brasileira de Linguistica Aplicada, Campinas, v. 5, n. 1, p. 181-207, 2005. 
A construção do curriculo nos cursos de letramento de jovens e adultos não escolarizados, 2006. Disponivel em: http://www.cereja.org.br/arquivos/uploads/ sylviaterzy.pdf. Acesso em: 08 mai. 2008.

TODARO, Mônica de Ávila; PEREIRA, Daniel de Aguiar. Paulo Freire e o corpo consciente. ANAIS... 37 a Reunião Nacional da ANPEd - 04 a 08 de outubro de 2015, UFSC - Florianópolis.

TORQUATO, R.; MASSI, G.; SANTANA, A. P. (2011). Envelhecimento e

Letramento: A Leitura e a Escrita na Perspectiva de Pessoas com Mais de 60 Anos de Idade. Psicologia: Reflexão e Crítica, 24(1), 89-98, 2011.

WHITTEMORE R, KNAFL K. The integrative review: update methodology. J Adv Nurs:52(5):546-53, 2005.

Recebido em 26 ago. 2018 / Aprovado em I6 out. 2018

\section{Para referenciar este texto:}

PEREIRA, D. A.; OLIVEIRA, E. F.; CACHIONI, M. Revisão integrativa: letramentos do idoso e os círculos de cultura freireanos. EccoS - Revista Científica, São Paulo, n. 47, p. 419-439. set/dez. 2018. Disponível em: <https://doi.org/I0.5585/ EccoS.n47.I0313>. 
